INTERSTITIAL LUNG DISEASE

\title{
British Thoracic Society Study on cryptogenic fibrosing alveolitis: response to treatment and survival
}

\author{
Robin M Rudd, Robin J Prescott, J C Chalmers, lan D A Johnston, for the Fibrosing Alveolitis \\ Subcommittee of the Research Committee of the British Thoracic Society
}

See end of article for authors' affiliations

\section{Correspondence to:} Dr R M Rudd, London Chest Hospital, Bonner Road, London E2 9JX, UK dr@robinrudd.com

Received 21 April 2005

Accepted 17 May 2006

Published Online First

9 June 2006
Thorax 2007;62:62-66. doi: 10.1136/thx.2005.045591

Background and objective: The initial results of a survey of 588 patients with a clinical presentation of cryptogenic fibrosing alveolitis (CFA) also known as idiopathic pulmonary fibrosis, have been published. This article reports further results pertaining to response to treatment and survival.

Methods: Data on the treatment given and lung function response were collected over 4-6 years. Survival data were collected over 10 years.

Results: Treatment was given to 445 (76\%) patients, 55\% were given prednisolone alone and the remainder another immunosuppressive agent, usually with prednisolone. Treated patients had worse lung function initially. At 3 months after study entry, treated patients were more likely to have improved forced vital capacity (FVC) than the untreated patients. Patients whose FVC improved were younger $(p=0.001$ analysis of variance (ANOVA)) and had lower initial FVC ( $<<0.001$, ANOVA). Patients who responded to treatment at 3 months or at 1 year survived longer than those who remained stable, who in turn survived longer than those who deteriorated $(p=0.002)$. These differences were largely accounted for by patients with better lung function surviving longer. Younger age at entry, female sex and higher percentage predicted FVC and reduced carbon monoxide transfer factor at study entry were associated with greater chances of survival at 4 years. Overall median survival from entry was 2.43 years ( $95 \%$ confidence interval (CI) 2.17 to 3.18 ). Conclusions: About a third of patients with CFA showed improved lung function after initiation of corticosteroid or immunosuppressive treatment, and those who improved survived longer. Poorer lung function, male sex and age are adverse prognostic features. Overall survival was poor.

n 1997, the initial results of a survey of 588 patients with cryptogenic fibrosing alveolitis (CFA) diagnosed and treated in the UK were published. ${ }^{1}$ Further analysis has been carried out to obtain information about the response to drug treatment and survival.

\section{METHODS}

\section{Study design}

The design of the study has been described previously. ${ }^{1}$ Briefly, this was an observational study of patients diagnosed with CFA, as it was then termed in the UK, corresponding to idiopathic pulmonary fibrosis (IPF) in US terminology. Patients entered the study between 1 December 1990 and 30 November 1992. Patients were followed up until November 1996 unless death occurred earlier. Information about survival and causes of death has been updated to 31 December 2000. Diagnostic criteria for our study were either a histological diagnosis of CFA or bilateral interstitial chest radiographic shadowing with bilateral basal inspiratory crackles, and lung function test results compatible with diffuse interstitial fibrosis-that is, a restrictive and/or gas transfer defect. ${ }^{1}$ Lung biopsy was performed in only $41 \%$ of patients. High-resolution computed tomography (HRCT) was not routinely performed at the time we recruited patients, and we did not collect data on HRCT findings. Occupational histories were recorded to exclude asbestosis and other known causes of diffuse pulmonary fibrosis, including extrinsic allergic alveolitis. Patients with systemic disorders associated with pulmonary fibrosis, such as collagen vascular diseases, were excluded.

Since the inception of the study, concepts and terminology of interstitial lung disease, particularly of what are now termed the idiopathic interstitial pneumonias (IIPs), have changed. ${ }^{2}$ The term IPF is preferred to CFA according to a joint statement of the American Thoracic Society and the European Respiratory Society. $^{2}$ An important distinction has now been drawn between IPF, with its HRCT and histological features corresponding to usual interstitial pneumonia (UIP), and nonspecific interstitial pneumonia which has a better prognosis. Most of our patients probably fell into the group now designated IPF or UIP, but it is likely that a substantial minority had other types of IIP. However, for the purposes of reporting this study, we considered it appropriate to use the terminology current at the time that patients entered the study (ie, 1990-2). The study therefore concerns patients with the clinical syndrome of CFA or IPF as then diagnosed rather than patients exclusively with IPF or UIP according to current diagnostic criteria.

\section{Drug treatment}

Drug treatment was administered entirely at the discretion of participating clinicians. The time at which treatment was commenced in relation to study entry and the initial regimen used were recorded.

\section{Response to treatment}

Responses to treatment were defined in terms of changes in lung function (table 1).

It was not appropriate to analyse in detail the changes in various lung function measurements because the frequency of missing data would have resulted in small subgroups. For

Abbreviations: ANOVA, analysis of variance; CFA, cryptogenic fibrosing alveolitis; FVC, forced vital capacity; HRCT, high-resolution computed tomography; IIP, idiopathic interstitial pneumonia; IPF, idiopathic pulmonary fibrosis; TLCO, reduced carbon monoxide growth factor; UIP, usual interstitial pneumonia 
Table 1 Responses to treatment

\begin{tabular}{ll}
\hline Response & Definition \\
\hline Improved & $\begin{array}{l}\text { Increase of } \geqslant 10 \% \text { in FVC or TLCO without decrease of } \\
\geqslant 10 \% \text { in either }\end{array}$ \\
Unchanged & $\begin{array}{l}\text { Increase or decrease by }<10 \% \text { in FVC and TLCO; or } \\
\text { increase of } \geqslant 10 \% \text { in FVC or TLCO with decrease of } \geqslant 10 \% \\
\text { in the other }\end{array}$ \\
Worse & $\begin{array}{l}\text { Decrease of } \geqslant 10 \% \text { in FVC or TLCO without increase of } \\
\geqslant 10 \% \text { in either }\end{array}$ \\
\hline
\end{tabular}

FVC, forced vital capacity; TLCO, reduced carbon monoxide transfer factor. FVC better and TLCO worse ( 8 patients), or FVC worse and TLCO better ( 5 patients), were counted as unchanged.

assessment of the initial response to treatment, change in forced vital capacity (FVC) alone was used because substantially more data were available at 3 months for FVC than for reduced carbon monoxide transfer factor (TLCO). For other time points, simple categories of response to treatment were defined using the most frequently available and relevant measurements-that is, FVC and TLCO.

\section{Statistical analysis}

Student's t test was used to compare baseline characteristics of patients treated at or within 3 months of study entry with those patients treated later or not at all. Analysis of variance (ANOVA) was used to compare baseline characteristics of patients who responded to treatment in different ways. Proportions were compared using the $\chi^{2}$ test and the $\chi^{2}$ test for trend. Survival was analysed using log rank tests, based on the total survival experience; logistic regression, based on survival at a fixed point in time; and the Cox proportional hazards model. Statistical significance was considered at $\mathrm{p}<0.05$.

\section{RESULTS}

\section{Treatment used}

Treatment was given at some time during the course of the study in 445 of 588 (76\%) patients, including a minority (7\%) of patients in whom treatment had already been commenced before they entered the study. Table 2 shows the times of commencement of treatment.

In all, $55 \%$ received prednisolone alone, $23 \%$ up to $30 \mathrm{mg}$ daily and $33 \%$ received $>30 \mathrm{mg}$ daily; $12 \%$ received prednisolone in combination with other drugs, mainly azathioprine or cyclophosphamide; and 2\% received another drug alone. The $7 \%$ treated before study entry had mostly received prednisolone.

\section{Pretreatment characteristics}

Compared with patients receiving treatment later than 3 months from study entry or never, patients started on

Table 2 Time of commencement of treatment after diagnosis $(n=588)$

\begin{tabular}{ll}
\hline Interval from diagnosis & $\mathbf{n}(\%$ of total) \\
\hline 3 months & $289(49)$ \\
$3-6$ months & $25(4)$ \\
$6-12$ months & $21(4)$ \\
$>12$ months & $70(12)$ \\
On treatment at study entry & $40(7)$ \\
Never treated & $143(24)$ \\
Total & $588(100)$ \\
\hline
\end{tabular}

treatment at study entry or within 3 months did not differ with respect to age (mean $67 v 68$ years, NS), but had worse lung function (percentage predicted TLCO 46\% v 54\%, percentage predicted FVC $71 \% v 86 \%, \mathrm{p}<0.001$ in each case).

\section{Response to treatment and change in lung function over time}

At 3 months after study entry, data on lung function were available for 296 patients, representing $56 \%$ of those still alive. Among 155 patients started on treatment, 56 (36\%) had improved FVC by $\geqslant 10 \%, 68(44 \%)$ were stable and $31(20 \%)$ had worsened FVC by $\geqslant 10 \%$. A higher proportion of patients treated had improved FVC at 3 months compared with patients not treated $(9 / 129,7 \%)$, this being the case whether the denominator was restricted to patients with lung function data $\left(\chi_{\text {trend }}^{2}=11.6, p<0.001\right)$ or the total number of treated patients $(\mathrm{p}<0.01)$. Patients who responded to treatment by improvement in FVC at 3 months were younger $(p=0.001$, ANOVA) and had lower initial percentage predicted FVC $(p<0.001$, ANOVA) than patients who did not, but this did not differ significantly with respect to percentage predicted TLCO.

Lung function status in relation to time of commencement of treatment was analysed at annual intervals after study entry using the simple better, same and worse categories combining FVC and TLCO.

Lung function data within 3 months either side of the year end were used, but even so data were unavailable for substantial numbers of patients. At 1 and 2 years, we found no significant difference in the frequency of improved, stable or worse lung function according to whether treatment had been started within 3 months, between 3 and 12 months or not at all. However, at 3 and 4 years, those started on treatment at entry or within 3 months of entry were more likely to have improved lung function and less likely to have worse lung function compared with that at entry than those started on treatment later or not at all (table 3 ).

\section{Survival}

Follow-up data on vital status were available for all 588 patients. At 4 years from study entry, 355 (60.4\%) had died. Overall median survival from entry was 2.43 years $(95 \%$ confidence interval (CI) 2.17 to 3.18).

Survival at 4 years from entry was analysed by logistic regression using vital status at that time point as the dependent variable, and age, sex, percentage predicted FVC and percentage predicted TLCO as independent variables. Data were available for 427 of 588 cases; 19 patients alive but $<4$ years from study entry were excluded from this analysis.

Younger age at entry, female sex, and higher percentage predicted FVC and TLCO were associated with greater chances of survival at 4 years. The result of the logistic regression on these variables was as follows:

$\log ($ odds $)=1.14-0.0602 \times$ age $-0.7883 \times$ sex $+0.0214 \times \% \mathrm{FVC}+$ $0.0258 \times \%$ TLCO

where odds represents the probability of survival divided by the probability of death. Smoking status did not affect survival significantly after allowing for the age, sex and initial lung function. Survival analyses using the Cox proportional hazards model with allowance for missing values gave conclusions qualitatively similar to those of logistic regression.

Log rank tests showed that patients who were not started on treatment before or at study entry survived longer than those who were treated before or at study entry. Similarly, those who were still not started on treatment by 3, 6, 12, 24 and 36 months from study entry survived longer from those points 
Table 3 Lung function status at various intervals in relation to time of starting treatment

\begin{tabular}{|c|c|c|c|c|}
\hline $\begin{array}{l}\text { Interval from } \\
\text { study entry }\end{array}$ & $\begin{array}{l}\text { Lung function } \\
\text { compared with } \\
\text { baseline }\end{array}$ & $\begin{array}{l}\text { Treatment started at } \\
\text { entry or within } 3 \text { months } \\
\text { of entry, } n(\%)\end{array}$ & $\begin{array}{l}\text { Treatment started } \\
\text { later or not at } \\
\text { all, } n(\%)\end{array}$ & $\begin{array}{l}\chi^{2} \text { test for trend, } \\
\text { p value }\end{array}$ \\
\hline 1 year & & $n=71$ & $\mathrm{n}$ with data $=116$ & \\
\hline 173 dead & Better & $26(37)$ & $24(21)$ & $\chi^{2}=2.2$, \\
\hline 411 alive & Same & $16(22)$ & $42(36)$ & $\tilde{p}=0.14$ \\
\hline 4 unknown* & Worse & $29(41)$ & $50(43)$ & \\
\hline 2 years & & $\mathrm{n}=49$ & $n=92$ & \\
\hline 254 dead & Better & $15(31)$ & $17(19)$ & $\chi^{2}=0.2$, \\
\hline 324 alive & Same & $6(13)$ & $28(30)$ & $\tilde{p}=0.67$ \\
\hline 10 unknown* & Worse & $28(57)$ & $47(51)$ & \\
\hline 3 years & & $\mathrm{n}=35$ & $n=66$ & \\
\hline 311 dead & Better & $17(49)$ & $7(11)$ & $\chi^{2}=14.1$ \\
\hline 261 alive & Same & $4(11)$ & $14(21)$ & $p<0.001$ \\
\hline 16 unknown* & Worse & $14(40)$ & $45(68)$ & \\
\hline 4 years & & $n=25$ & $\mathrm{n}=52$ & \\
\hline 355 dead & Better & $10(40)$ & $4(8)$ & $\chi^{2}=9.1$ \\
\hline 195 alive & Same & $4(16)$ & $12(23)$ & $\hat{p}=0.003$ \\
\hline 38 unknown* & Worse & $11(44)$ & $36(69)$ & \\
\hline
\end{tabular}

than those started on treatment by the corresponding times (all differences, $\mathrm{p}<0.05$ ).

Among those treated, we found no significant differences in proportion alive at 4 years between drug treatment groupsthat is, prednisolone $\geqslant 30 \mathrm{mg}$ daily $(33 \%)$, prednisolone $<30 \mathrm{mg}$ daily (38\%), prednisolone plus another drug (31\%), another drug alone (22\%) and treated before study entry (27\%).

Of the 445 patients who had received treatment, 150 (34\%) were alive compared with 83 of $143(58 \%)$ of those never treated $(\mathrm{p}<0.001)$.

Among patients who were treated, we found no significant differences in survival from commencement of treatment according to the time of commencement of treatment (before entry, <3 months of entry, 3-6 months, 6-12 months or $>12$ months) or according to the drug regimen used (prednisolone alone in doses of $<30 \mathrm{mg}$ daily or $\geqslant 30 \mathrm{mg}$ daily, prednisolone plus another drug or another drug alone).

The effect of response to treatment on survival from the time of response assessment was assessed by comparing better, same

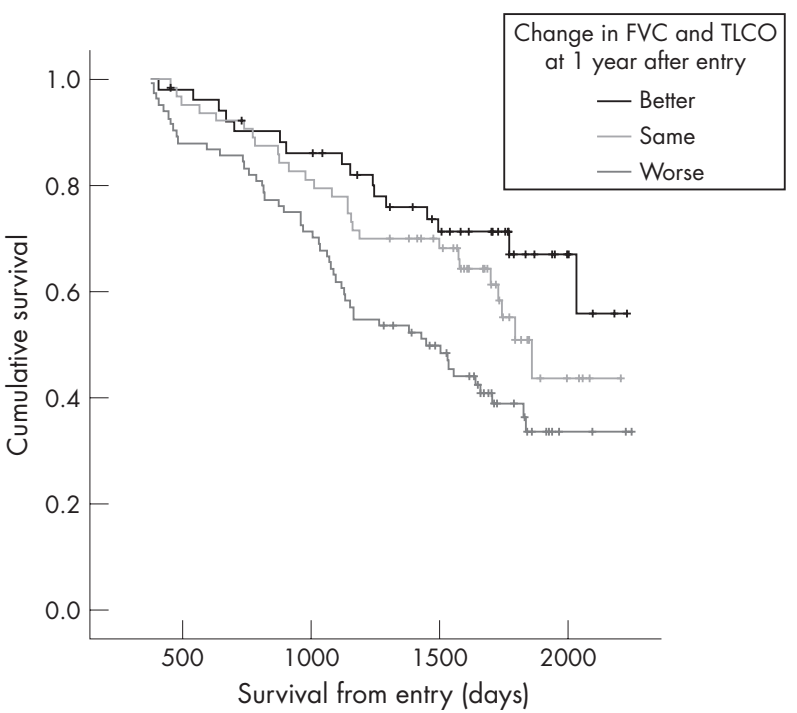

Figure 1 Survival according to treatment response assessed at 1 year. Differences between groups significant by the log rank test, $p=0.002$. FVC, forced vital capacity; TLCO, reduced carbon monoxide transfer factor. and worse lung function categories using the log rank test. Patients who responded to treatment at 3 months survived significantly longer than those who remained stable, who in turn survived substantially longer than those who deteriorated $(\log$ rank $\mathrm{p}=0.015)$. The differences were similar but greater when the analysis was based on response assessed at 1 year $(p=0.002$; fig 1$)$. These differences were largely accounted for by lung function levels at 3 months and at 1 year, those with better lung function surviving longer (fig 2). After allowing for percentage predicted FVC or percentage predicted TLCO, differences between response categories were no longer significant $(\mathrm{p}=0.52$ at 3 months, $\mathrm{p}=0.60$ at 1 year $)$.

\section{Causes of death}

Table 4 shows the causes of death updated to 31 December 2000 .

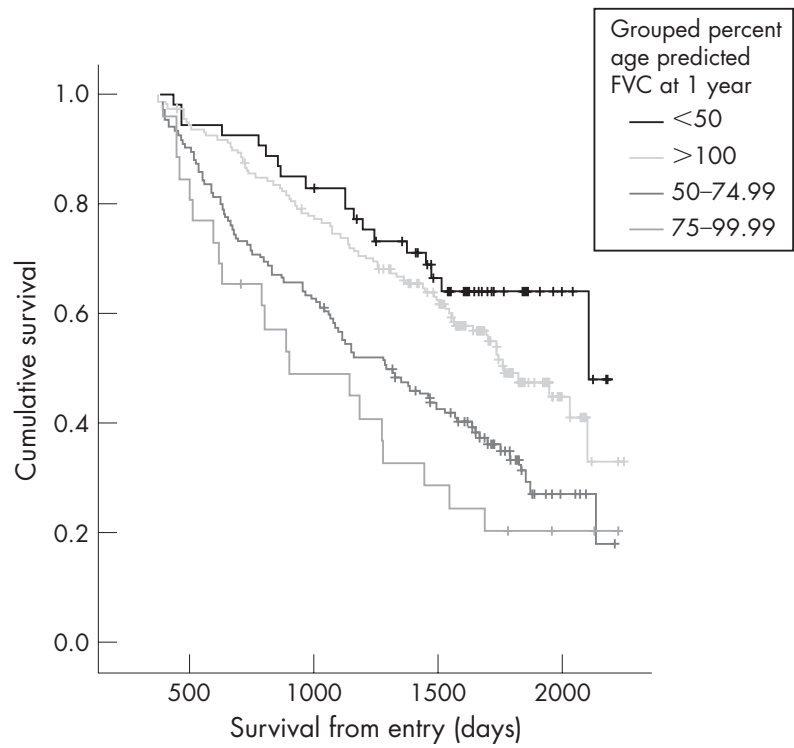

Figure 2 Survival according to percentage predicted forced vital capacity (FVC) at 1 year. Differences between groups significant by the log rank test, $\mathrm{p}<0.001$. FVC, forced vital capacity. 


\begin{tabular}{|c|c|c|c|c|c|c|}
\hline & $\begin{array}{l}\text { Primarily } \\
\text { CFA }\end{array}$ & $\begin{array}{l}\text { Partly } \\
\text { CFA }\end{array}$ & $\begin{array}{l}\text { Partly CFA with } \\
\text { lung cancer }\end{array}$ & $\begin{array}{l}\text { Other cause with } \\
\text { lung cancer }\end{array}$ & $\begin{array}{l}\text { Other } \\
\text { cause }\end{array}$ & Total \\
\hline $\begin{array}{l}\text { Treated before } \\
\text { entry }\end{array}$ & $19^{*}$ & 5 & 2 & 0 & 5 & 31 \\
\hline $\begin{array}{l}\text { Treated within } \\
3 \text { months }\end{array}$ & $135^{*}$ & 45 & 15 & 2 & 23 & 220 \\
\hline Treated later & 46 & 10 & 8 & 1 & 16 & 81 \\
\hline Never treated & $15^{*}$ & & & 7 & 18 & 66 \\
\hline Total & $215(54 \%)$ & 77 (19\%) & $34(9 \%)$ & $10(3 \%)$ & $62(16 \%)$ & 398 \\
\hline \multicolumn{7}{|c|}{$\begin{array}{l}\text { CFA, cryptogenic fibrosing alveolitis. } \\
\text { "Includes one case designated primarily CFA but with lung cancer. } \\
\text { Cases in which CFA was listed in part } 1 \text { of the death certificate as the main or underlying cause of death were designatec } \\
\text { "death primarily due to CFA" and cases in which CFA was listed in part } 2 \text { of the death certificate, meaning a } \\
\text { contributory cause of death unrelated to the main cause of death, were designated "death partly due to CFA". }\end{array}$} \\
\hline
\end{tabular}

CFA was the main or a contributory cause of death in 292 of 398 (73\%) deaths. Lung cancer was present in 47 (12\%) patients at death.

\section{DISCUSSION}

This study is the largest ever reported on CFA, and unlike most previous series, includes patients presenting to respiratory physicians in a wide variety of settings, rather than just patients referred to specialist centres. Data collection on deaths is complete and conclusions about survival are more secure than those regarding changes in lung function that are based on incomplete data. Despite a clearly defined protocol of assessments at specific time points, substantial data were lost in the follow-up period, particularly on lung function. This was perhaps inevitable in a study involving a large number of doctors seeing patients in a routine clinical setting. It seems likely that doctors would offer extended intervals between follow-up assessments to untreated patients with stable disease. If this were the case, then the treatment effects observed are likely to be underestimated. Overall, however, it is not possible to predict with any certainty the effect of the loss of data points.

A response to treatment by improvement in FVC occurred in just over one third of patients. This is consistent with data from other studies showing that improvement in lung function occurs in $25-40 \%$ of patients with the clinical presentation of CFA after commencement of corticosteroid or immunosuppressive treatment. ${ }^{3-6}$ Lung function improved after study entry more frequently in those who were treated within 3 months of study entry than in those treated later or not at all. This may have reflected more active disease in patients treated within 3 months, as suggested by their more severely impaired lung function when treatment was started. More frequent response in patients with more severe initial impairment of lung function has been noted previously. ${ }^{4}{ }^{57}$ An association between response and a shorter interval between onset of symptoms and commencement of treatment has also been found. ${ }^{4}$ These features have been postulated to reflect an active stage of the disease, but may also be demonstrating regression to the mean.

In an observational study, the evidence cannot prove that the improvements were a result of treatment. However, the observations that improvements in lung function, which in some cases lasted for at least 4 years, were more frequent in treated than in untreated patients, and in patients treated earlier rather than later, might reasonably be interpreted as suggesting that the improvements were more likely a result of treatment rather than coincidental to it.

Patients who responded to treatment survived longer than those who did not, a feature which has been reported previously, ${ }^{3-5}$ and patients with stable disease survived longer than those who deteriorated on treatment, also reported previously. ${ }^{6}$ These observations cannot of course prove that treatment influenced survival in responders who might have been patients with an inherently better prognosis. However, as better baseline lung function and better lung function at 1 year were independently associated with longer survival, it is reasonable to speculate that the improvements in lung function that followed early treatment may have been associated with improved survival for those patients who responded to treatment. Our findings did not suggest that higher doses of corticosteroids, or a combination of a corticosteroid with an immunosuppressive agent, were more likely to be associated with improvement in lung function, although interpretation of this observation is complicated by the possibility that higher doses and additional agents may well have been used for patients with more severe disease.

In considering the relevance of this study's findings to current practice, an initial question is whether the therapeutic options have markedly changed since 1990-6, the period over which our data were collected. No published information is available on current treatment choices offered by doctors, but in routine practice the options are essentially unchanged-that is, steroids and/or immunosuppressants (eg, azathioprine and cyclophosphamide), ${ }^{8}$ now with the probable addition of acetyl cysteine. ${ }^{9}$ Interferon $\gamma$ seemed to be promising in a small study, ${ }^{10}$ but other studies including a recent large randomised trial showed no benefit. ${ }^{11}{ }^{12}$ Several other approaches to treatment are being explored, ${ }^{13}{ }^{14}$ but have not yet entered routine practice in the UK. Thus, in terms of the drugs used, our findings are relevant to current day-to-day practice.

What effect are the changed concepts and diagnostic criteria of the IIPs ${ }^{2}$ likely to have on the interpretation of our study findings in relation to treatment effects? HRCT is now integral to making a diagnosis in many patients with interstitial lung disease, ${ }^{8}$ whereas in the early 1990s, computed tomography was neither routine nor part of the accepted diagnostic criteria for CFA. It is likely therefore that within our study population there are patients with IPF, non-specific interstitial pneumonia and potentially some other IIPs. The survival of our patients was similar to that in recent studies that have specifically focused on IPF using computed tomography/lung biopsy criteria for diagnosis for UIP. ${ }^{15-19}$ However, our patients were older, and as age is an adverse prognostic factor in this and other studies, the comparable survival suggests that our cohort did include a proportion of patients with other IIPs with a better prognosis than UIP. Although our findings that a third of patients respond to treatment are in broad agreement with previous studies on CFA, based on both clinical and computed tomography/biopsy criteria, ${ }^{50-23}$ and reflect the outcome of the clinical syndrome of CFA, responses to treatment have been more disappointing in studies on patients with biopsy-proved UIP. ${ }^{24} 25$

The adverse prognostic relevance of worse lung function at presentation was confirmed. ${ }^{15}{ }^{26}$ The higher death rate among 
patients started on treatment than among those not treated at each time point possibly reflects the fact that those started on treatment had more severe breathlessness and worse lung function, indicating more severe disease, as reported previously. ${ }^{1}$ Poorer survival among patients treated with corticosteroids has been reported previously and has been thought to reflect treatment selection policy. ${ }^{15}$ At first sight, it might be perceived that there is a contradiction between the better survival in responders to treatment and the worse survival in patients treated than those not treated. The explanation is probably that among patients deteriorating more rapidly with worse lung function who are selected for treatment, a minority of patients respond to treatment and do better whereas the majority do not respond and do badly. Data from observational studies cannot prove that treatment influences survival. Such an effect could be identified only in a randomised study comparing treatment with no treatment, and there are no such satisfactory studies in the literature. ${ }^{27}$ The ethics of such a study could be debated in view of, on the one hand, good observational evidence from this and other studies that improvement in lung function occurs more often in treated patients and that better lung function is independently associated with longer survival, and on the other hand, the morbidity of steroid and other treatments.

Overall survival at just $<2.5$ years was poor, showing the gravity of this condition in an unselected patient population. Previous case series from specialist centres have reported substantially better median survival of the order of 45 years. ${ }^{3252728}$ A population-based registry study in New Mexico reported a median survival of 4.2 years. ${ }^{29}$ However, the survival of incident cases of CFA in a population-based study in England was similar to that in our study at 2.9 years, ${ }^{8}$ and most, although not all, recent studies also show that patients with UIP have a median survival of $<3$ years. ${ }^{16-19}$ Lung cancer was present in $12 \%$ of patients at death. A case-control study in which matched controls have been identified for the patients with CFA in the present study is in progress to investigate whether this represents a marked excess as has been reported previously. ${ }^{30}{ }^{31}$

This study is the largest ever reported on patients with CFA, and has been largely confirmatory of findings from previous smaller studies. It has particularly highlighted the poor overall survival in CFA, the response to treatment in about a third of patients and the longer survival associated with response to treatment, although we readily acknowledge that only a randomised study can confirm any treatment effect. The study has also shown that it is possible to gain the cooperation of a large proportion of UK respiratory physicians for a study on interstitial lung disease requiring data collection over a long period. This bodes well for future randomised studies on treatment of interstitial lung disease.

\section{ACKNOWLEDGEMENTS}

We thank the 150 members of the British Thoracic Society who participated in this study supported by the Morriston-Davis Trust. Members of the Fibrosing Alveolitis Subcommittee when the study was carried out were RAL Brewis (chairman), IDA Johnston, RM Rudd (study co-ordinators), RJ Prescott (statistician), J White and JAR Friend. We also thank our research assistants Mrs R Ryan and Mrs VE Johnston for their hard work and enthusiasm for the study throughout.

\footnotetext{
Authors' affiliations

Robin M Rudd, London Chest Hospital, Bonner Road, London, UK

Robin J Prescott, J C Chalmers, Medical Statistics Unit, Public Health Sciences, University of Edinburgh, Edinburgh, UK

Ian D A Johnston, University Hospital, Nottingham, UK

Competing interests: None.
}

Ethical approval: Ethical approval for the study was obtained from Nottingham University Hospital medical ethics committee, Nottingham, UK.

\section{REFERENCES}

1 Johnston IDA, Prescott RJ, Chalmers JC, et al. British Thoracic Society Study of cryptogenic fibrosing alveolitis: current presentation and initial management. Thorax 1997:52:38-44.

2 American Thoracic Society, European Respiratory Society. American Thoracic Society/European Respiratory Society International Multidisciplinary Consensus Classification of the Idiopathic Interstitial Pneumonias. Am J Respir Crit Care Med 2002; 165:277-304.

3 Turner-Warwick M, Burrows B, Johnson A. Cryptogenic fibrosing alveolitis: clinical features and their influence on survival. Thorax 1980;35:171-80.

4 Rudd RM, Haslam PL, Turner-Warwick M. Cryptogenic fibrosing alveolitis: relationship of pulmonary physiology and bronchoalveolar lavage to response to treatment and prognosis. Am Rev Respir Dis 1981;124:1-8.

5 Gay SE, Kazerooni EA, Toews GB, et al. Idiopathic pulmonary fibrosis. Predicting response to therapy and survival. Am J Respir Crit Care Med 1998; 157:1063-72.

6 Hanson D, Winterbauer RH, Kirtland SH, et al. Changes in pulmonary function test results after 1 year of therapy as predictors of survival in patients with idiopathic pulmonary fibrosis. Chest 1995;108:305-10.

7 van Oortegem K, Wallaert B, Marquette $\mathrm{CH}$, et al. Determinants of response to immunosuppressive therapy in idiopathic pulmonary fibrosis. Eur Respir $J$ 1994:7:1950-7.

8 British Thoracic Society, Standards of Care Committee. The diagnosis, assessment and treatment of diffuse parenchymal lung disease in adults. Thorax 1999;54(Suppl 1):S1-30.

9 Demedts M, Behr J, Buhl R, et al. High dose acetylcysteine in idiopathic pulmonary fibrosis. N Engl J Med 2005;353:2229-42.

10 Ziesche R, Hofbaver E, Wittmann K, et al. A preliminary study of long-term treatment with interferon gamma- $1 \mathrm{~b}$ and low dose prednisolone in patients with idiopathic pulmonary fibrosis. N Engl J Med 1999;341:1264-9.

11 Prasse A, Muller K-M, Kurz C, et al. Does interferon- $\gamma$ improve pulmonary function in idiopathic pulmonary fibrosis. Eur Respir J 2003;22:906-11.

12 Raghu G, Brown KK, Bradford WZ, et al. A placebo controlled trial of interferon gamma-1b in patients with idiopathic pulmonary fibrosis. N Engl J Med 2004;350:125-33.

13 Azuma A, Nukiwa T, Tsuboi E, et al. Double blind placebo controlled trial of pirfenidone in patients with idiopathic pulmoanry fibrosis. Am J Respir Crit Care Med 2005;171:1040-7

14 Gross TJ, Hunninghake GW. Idiopathic pulmonary fibrosis. N Engl J Med 2001;345:517-25.

15 Hubbard R, Johnston I, Britton J. Survival in patients with cryptogenic fibrosing alveolitis: a population-based cohort study. Chest 1998;113:396-400.

16 Bjoraker JA, Ryu JA, Edwin MK, et al. Prognostic significance of histopathologic subsets in idiopathic pulmonary fibrosis. Am J Respir Crit Care Med 1998; 157:199-203.

17 King TE, Tooze J, Schwartz Ml, et al. Predicting survival in idiopathic pulmonary fibrosis. Am J Respir Crit Care Med 2001;164:1171-81.

18 Flaherty KR, Toews GB, Travis WD, et al. Clinical significance of histological classification of idiopathic pulmonary fibrosis. Eur Respir J 2002;19:275-83.

19 Latsi PI, du Bois RM, Nicholson AG et al. Fibrotic idiopathic interstitial pneumonia. The prognostic value of longitudinal functional trends. Am J Respir Crit Care Med 2003;168:531-7.

20 Turner-Warwick M, Burrows M, Johnson A. Cryptogenic fibrosing alveolitis: response to corticosteroid treatment and its effect on survival. Thorax 1980;35:593-9.

21 Tukiainen $\mathbf{P}$, Taskinen $E$, Holsti $P$, et al. Prognosis of cryptogenic fibrosing alveolitis. Thorax 1983;38:349-55.

22 Raghu G, Depaso WJ, Cain K, et al. Azathioprine combined with prednisone in the treatment of idiopathic pulmonary fibrosis: a prospective double-blind randomised placebo-controlled trial. Am Rev Respir Dis 1991;144:291-6.

23 Flaherty KR, Toews GB, Lynch JP, et al. Steroids in idiopathic pulmonary fibrosis: a prospective assessment of adverse reactions, response to therapy and survival. Am J Med 2001;110:278-82

24 Nicholson AG, Colby TV, Dubois RM, et al. The prognostic significance of the histologic pattern of interstitial pneumonia in patients presenting with the clinical entity of cryptogenic fibrosing alveolitis. Am J Respir Crit Care Med 2000;162:2213-17.

25 Carrington CB, Gaensler EA, Coutu RE, et al. Natural history and treated course of usual and desquamative interstitial pneumonia. N Engl J Med 1978;298:801-9.

26 Schwartz DA, Helmers RA, Galvin JR, et al. Determinants of survival in idiopathic pulmonary fibrosis. Am J Respir Crit Care Med 1994;149:450-4

27 Richeldi L, Davies HR, Ferrara G, et al. Corticosteroids for idiopathic pulmonary fibrosis [Cochrane review]. In: The Cochrane Library, Issue 2. Chichester: Wiley, 2004

28 Stack BHR, Choo-Kang YFJ, Heard BE. The prognosis of cryptogenic fibrosing alveolitis. Thorax 1972;27:535-42.

29 Mapel DW, Hunt WC, Utton R, et al. Idiopathic pulmonary fibrosis: survival in population based and hospital based cohorts. Thorax 1998:53:469-76.

30 Turner-Warwick M, Lebowitz M, Burrows B, et al. Cryptogenic fibrosing alveolitis and lung cancer. Thorax 1980;35:496-9.

31 Hubbard R, Venn A, Lewis S, et al. Lung cancer and cryptogenic fibrosing alveolitis. A population-based cohort study. Am J Respir Critical Care Med 2000;161:5-8. 


\section{PostScript}

\section{LETTER}

\section{Pulmonary hypertension in Hodgkin's disease}

We wish to share our experience in an unusual case presentation of pulmonary hypertension. A 48-year-old Caucasian female with a history of hypothyroidism and smoking presented with progressive dyspnoea on exertion for 3 years, markedly worse during the past 6 months. She also had arthralgias, Raynaud's phenomena, night sweats and a 25-pound weight loss over 6 months. Chest computed tomography scan showed diffuse mediastinal lymphadenopathy. Lymph node biopsy showed non-necrotising epithelioid granulomas compatible with sarcoidosis Symptoms worsened despite treatment with prednisone.

Pulmonary function tests showed mild restrictive disease, reduced diffusion capacity and desaturation during a 6-min walk. Echocardiogram showed a severely dilated and hypokinetic right ventricle. Right heart catheterisation showed pulmonary artery pressure $79 / 38 \mathrm{~mm} \mathrm{Hg}$ (mean $46 \mathrm{~mm} \mathrm{Hg}$ ), cardiac output $6.7 \mathrm{l} / \mathrm{min}$ and cardiac index $3.7 \mathrm{l} / \mathrm{min} /$ $\mathrm{m}^{2}$. There was no significant response to inhaled nitric oxide at $20 \mathrm{ppm}$.

A retrospective review of her pathology showed a dominant reaction pattern consistent with sarcoidosis, small foci of paracortical infiltration by large mononuclear and binucleated haematopoietic elements, and a concomitant background of tissue eosinophilia. Immunohistostaining was consistent with mixed cellularity Hodgkin's lymphoma (fig l).

She was initiated on epoprostenol by continuous infusion. Owing to her pulmonary and cardiac disease, she received six cycles of chlorambucil, vinblastine, procarbazine and prednisone. She achieved a complete response and remains in remission 20 months after chemotherapy. She continues on epoprostenol therapy with improved exercise tolerance. Repeat right heart catheterisation showed pulmonary artery pressure 48/21 (mean $30 \mathrm{~mm} \mathrm{Hg})$, cardiac output $7.8 \mathrm{l} / \mathrm{min}$ and cardiac index $4.6 \mathrm{l} / \mathrm{min} / \mathrm{m}^{2}$. Attempts to wean epoprostenol were unsuccessful.

Sarcoid-like reactions are defined as areas of non-caseating granulomas seen on biopsy in patients without symptoms of systemic sarcoidosis. Radiographically, patients with intrathoracic sarcoid-like reactions may present with hilar or mediastinal adenopathy, ground-glass infiltrates or a perivascular nodularity mimicking sarcoidosis. Among the various conditions associated with a sarcoid-like diathesis are infections, hypersensitivity reactions, and solid or haematological malignancies.

In malignancy, this pathology can be seen at the primary tumour site, particularly in $\mathrm{T}$ cell

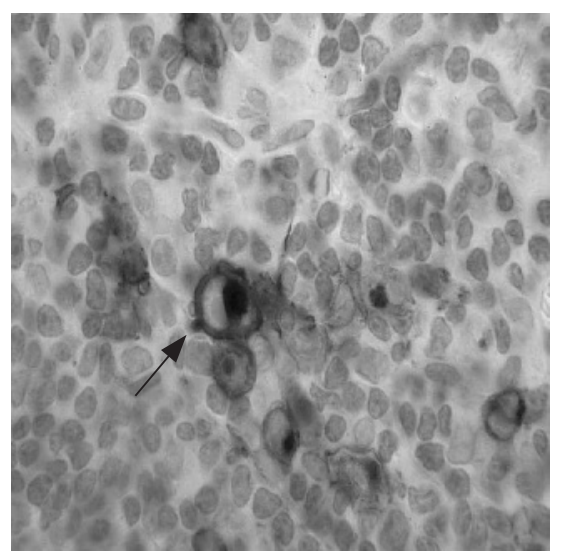

Figure 1 The neoplastic cell populace shows characteristic CD30 positivity (arrow) manifesting a sharp, cytoplasmic, membrane-like and perinuclear staining pattern (avidin biotin dibenzidine $\times 1000$ )

lymphoma and Hodgkin's disease, in lymph nodes draining the region, or in distant organs such as the spleen, liver or bone marrow. Up to $4.4 \%$ of patients with carcinoma, $7.3 \%$ of patients with non-Hodgkin's lymphoma and $13.8 \%$ of patients with Hodgkin's disease will feature sarcoid-like reactions. ${ }^{2}$

Pulmonary arterial hypertension (PAH) develops in up to $28 \%$ of patients with sarcoidosis. ${ }^{3}$ The aetiology of PAH in sarcoidosis is generally presumed to be secondary to parenchymal fibrosis and hypoxaemia. However, PAH may develop in patients without extensive parenchymal destruction secondary to perivascular or intravascular granulomatous inflammation, granulomatous angiitis, extrinsic compression of the main or peripheral pulmonary arteries by mediastinal lymph nodes or fibrosis with resultant pulmonary stenosis. $^{5}$

The response of PAH secondary to sarcoidosis in the treatment for sarcoidosis is uncertain in a case series, the haemodynamic response to steroid therapy was found to be lagging behind the radiographic and pulmonary function test improvement, and was not universally seen. In a small study, patients with severe $\mathrm{PAH}$ secondary to sarcoidosis were found responsive to vasodilator therapy. ${ }^{3} \mathrm{PAH}$ in association with sarcoid-like reactions is not described and management is unproven.

No cases of PAH secondary to a sarcoid-like reaction or Hodgkin's disease have been reported previously. This case underscores the association of lymphoma and sarcoid-like reactions, and the possibility that $\mathrm{PAH}$ in these patients may be underappreciated. This case also emphasises the importance of a systematic evaluation for lymphoproliferative disease in patients with lymphadenopathy presumed to be sarcoidosis.

Matthew Exline, Cynthia Magro, Thomas Lin Namita Sood

Department of Medicine, Department of Pathology, The Ohio State University, Columbus, OH 43210, USA

Correspondence to: N Sood, Department of Medicine, Department of Pathology, The Ohio State University, Columbus, OH, USA; namita.sood@osumc.edu doi: $10.1136 /$ thx.2006.070029

Competing interests: None declared.

\section{References}

1 Hunsaker AR, Munden RF, Pugatch RD, et al. Sarcoid-like reaction in patients with malignancy. Radiology 1996;200:255.

2 Brincker H. Sarcoid reactions and sarcoidosis in Hodgkin's disease and other malignant lymphomata. Br J Cancer 1972;26:120.

3 Preston IR, Klinger JR, Landzberg MJ, et al. Vasoresponsiveness of sarcoidosis-associated pulmonary hypertension. Chest 2001;120:866.

4 Salazar A, Mana J, Sala J, et al. Combined portal and pulmonary hypertension in sarcoidosis. Respiration 1994:61:117.

5 Nunes H, Humbert M, Capron F, et al. Pulmonary hypertension associated with sarcoidosis: mechanisms, haemodynamics and prognosis. Thorax 2006;61:68

6 Gluskowski J, Hawrylkiewicz I, Zych D, et al. Effects of corticosteroid treatment on pulmonary haemodynamics in patients with sarcoidosis. Eur Respir J 1990:3:403.

\section{CORRECTIONS}

doi: 10.1136/thx.2005.045591corr l

In the paper by Rudd et al (Thorax 2007;62:6266) from the January issue, the abbreviation TLCO was incorrectly expanded to "reduced carbon monoxide transfer factor", when in fact it should have been "carbon monoxide transfer factor". This occurs in the penultimate sentence of the results section of the abstract, the abbreviations list and the legend of figure 1 .

doi: 10.1136/thx.2006.73098corr 1

Incorrect reference details were inserted into reference 21 of the editorial by Wedzicha and Hurst, published in the February issue (Thorax 2007;62:103-104). The reference should not be Eur Respir J 2002;19:217. The correct reference details are: Eur Respir J, published online before print November 15, 2006 as doi: 10.1183/ 09031936.00092506 